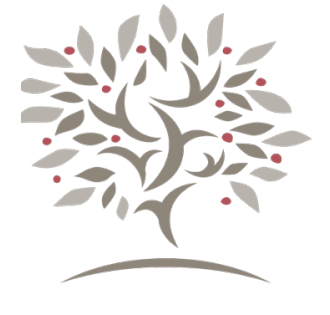

\title{
Experiencing Flow through an Integrative Pedagogy
}

\author{
Kirsten S. Oh \\ Azusa Pacific University
}

\begin{abstract}
A B S TRACT
Faculty face challenges of balancing many demands and needs from family, school, religious organizations, and different communities to which they belong. This article discusses integrative strategies for holding multiple roles and managing diverse demands from someone who has served as an administrator and professor and is a mother, wife, priest, and communal leader.
\end{abstract}

\section{KEYWORDS :}

flow, holistic, integrative pedagogy, Yin-Yang, self-care, contingency times

I walked back to my office feeling elated. I had experienced flow while lecturing and a sense of satisfaction filled my otherwise tired, end-of-semester body. Positive psychologist, Mihaly Csíkszentmihalyi, describes flow as "being completely involved in an activity for its own sake. The ego falls away. Time flies. Every action, movement, and thought follows inevitably from the previous one, like playing jazz. Your whole being is involved, and you're using your skills to the utmost" (Encyclopedia.com 2019). My 85-minute class seemed to have flown by without any consciousness of the flipped course instruction that created an active learning environment. The creativity of this learner-centered class session followed a natural progression of various sections comprised of lecture, reflective writing, group discussion, and class sharing.

It was the last lecture of the fall semester. I scanned the room full of 54 , mostly freshmen students with whom I had journeyed through their first semester of college. As a general education course in a large, private Christian university in California, this course introduced students to Christian beliefs, life, and service. The students demonstrated a combination of academic theories that resulted in an integrated praxis. The structure of this introductory, general education course was largely due to an ever-evolving design I had planned and improved upon for the last eight or more semesters grounded in current events, recent publications, and student demographics. Because of this complexity, I enjoyed the challenge of teaching this class, always hopeful that what and how I taught made a difference. However, I had not experienced this type of flow before. In this experience of being completely immersed in the teaching moment, I was cognizant that something had changed in me.

The intersections of my multiple identities and roles had somehow coalesced in this class session. In particular, the privilege of being a new mother in addition to all the other roles: professor, pastor, counselor, mentor, scholar, 
writer, wife, daughter, sister, and friend intensified my perception of and experience with these students. These students were beloved young adults; their parents or guardians had entrusted the formative years of their college life to my academic institution, and in turn, to me as their teacher. In retrospect, I realize the experience of flow in this aforementioned class was a happy confluence of presenting my whole self in class coupled with a deep concern for the students and their learning. This is part and parcel of what integrative pedagogy can produce.

\section{Balancing Professional, Personal, and Community Needs? A Case for Integrative Pedagogy}

The word "balance" has two distinct connotations. One is the keeping in tension of two opposing things while the other is juggling multiple worthwhile or good things. For me, the notion of the work-life balance evokes both connotations. Shaped by a cultural framework of "both-and" derived from a nonlinear, holistic, and dynamic Eastern philosophy of the Tao as reflected in the Korean flag's four trigrams surrounding the red and blue circle, I am oriented to hold multiple things in tension rather than to compartmentalize competing sectors of my life. I subscribe to an integrative model espoused by a dialectic Yin-Yang worldview in which "all phenomena are shaped by the dynamic integration of opposite yet complimentary elements" (Beveridge, Vallat, and De La Robertie 2018).

While the cultural framework I grew up with naturally oriented me to this integrative approach to teaching that incorporates my various roles and identities within a reciprocal human dimension, I was advised against it when I first entered the higher education workforce. I received wonderful advices from experienced professors and administrators; however, there was also a piece of advice that was not so helpful in my teaching career. It went something like this: "In order to preserve some form of sanity in your life in this complex world of higher education, you should compartmentalize your life; separate your personal from your professional life." Inadvertently, I entered the balance dilemma, to compartmentalize or not to compartmentalize.

This mantra did help me to leave my professional work as an administrator behind when returning home to my personal and communal life. The drive to and from work was my transitional time between professional work and personal/communal life (although friendships formed at work became part of my communal life). However, as a professor, this compartmentation of my professional, communal, public, and private selves seemed to compete with, and even dismantle, the very fiber of a practical theologian whose teaching pursues the tenets holistic integration. My experiences in the classroom have taught me to reclaim my cultural heritage and the cyclical nature of the multiple roles and identities that form, in-form, and reform each other.

My Asian heritage recognizes and embraces paradoxes (within my multiple roles) as inevitable, persistent, and even desirable with the following three key tenets of dialectical thinking:

a. The principle of change indicating that reality is a dynamic, perpetually changing process

b. The principle of contradiction suggesting that opposites exist in everything and are mutually complementary

c. The principle of relationship and holism suggesting that nothing is isolated and independent (Peng and Nisbett 1999)

These principles help me live within the dynamic nature of reality. That is, personal, communal, and professional spheres are contextually integrative and interdependent. As a member of the sandwich generation who loves and cares for a toddler and for aging parents, my research, writing, and teaching recalibrates my heart to persist more patiently. As a pastor of the local and global Methodist church, my passion for the liberating and transformative power of the Good News means I need to bring my whole self to preach, teach, counsel, serve, and worship. As a professor at a teaching university, it is imperative to keep all parts of myself, including my parental heart, as an integral piece of the pedagogical craft. I

$114 \quad 2021 ; 2: 1113-118$ The Wabash Center Journal on Teaching

This work is licensed under a Creative Commons Attribution-NonCommercial 4.0 International License 
adhere closely to what Martin Seligman confirms: "People who can make an explicit connection between their work and something socially meaningful to them are more likely to find satisfaction, and are better able to adapt to the inevitable stresses and compromises that come with working in the world" (Seligman 2012).

When I bring my whole, dynamic and changing self to the classroom and interact with the whole dynamic selves of the students intersubjectively in an integrative pedagogy, I am aware of the "constant stream of fast-paced, important, inthe-moment decisions" that are the fulcrum of an integrative pedagogy (Copeland 2016). Such intersubjectivity means the students and I co-create situation-specific, context-driven, priority-setting norms within the parameters of the designated learning outcomes. At the core of this approach is the understanding that "significant learning is learning that makes a difference in how people live-and the kind of life they are capable of living. ..” (Fink 2013). Students embrace significant learning that impacts how they live precisely because they co-create the learning experience. However, because students are encouraged to engage in their own learning through the process of co-creating, controlled chaos may ensue especially in the uncertain spaces when more than one good decision emerge.

Moreover, sharing life in this integrated approach to teaching inevitably means that I draw stories from my own life. At times, this openness leads to a deep sense of vulnerability. The fear of oversharing versus the desire to be authentic tempers what and how much actually gets shared to prevent some all too vulnerable moments. For instance, disclosures of failures or mistakes to illustrate a point may end up missing the point entirely, and such confessions may leave me quite raw and sensitive. At the same time, the value of honesty and authenticity outweighs any presentation of false perfection. This healthy ambivalence provides the necessary tension to consider the collateral cost to sharing life.

The integrative pedagogy does not achieve a perfectly balanced life. In fact, such a life is an illusion according to Stephen Brookfield in Skillful Teaching: "Perfection is sometimes thought of as achieving balance. This state of balance is also illusory ... Perhaps the most we can hope for is to keep these seeming opposites in a state of reasonably congenial tension. Working on the edge of tension, not achieving balance, is the name of the game" (Brookfield 2015). Instead, the integrative approach provides the permission to become more acquainted with our finite, limited selves. With this permission for the imperfect holding of tension, comes the awareness of the need for self-care and for the construction of contingency times.

\section{Self-Care}

The analogy of the airline attendants' instruction to place the oxygen mask on yourself first before you attend to others who need your assistance is apropos here to describe this self-care necessity. The element of self-care noted here is not just an individual desire for self-achievement or actualization, but one that promotes relational and reflexive paradigms that are prerequisite for building an integrative teaching model (see Knapik and Laverty 2018). In other words, self-care is not about putting ourself first or sacrificing others. Instead, it is about understanding the self in the multiplicity of our roles and caring for self in order to reinvigorate and recharge so self-awareness is possible. The space created by self care leads to recognizing how these various roles affect the self and those in our diverse relational webs.

Although I knew this notion of self-care was fundamental to my sense of wellbeing, I neglected this aspect of my life for the sake of urgent, immediate need such as infant-care being a new mother. When this tyranny-of-the-urgent took over the essentials of prolonged uninterrupted sleep and regular physical exercise, it resulted in a lack of focus on the various tasks my roles required. Even the basic walk to and from classes became a hurdle. During the first year and a half of my child's life, I managed to sprain my left ankle three times and needed to get appropriate treatments each time reminding me to slow down, assess, and realign myself.

I realized once again that I needed to practice self-care in order to flourish in my multiple roles. Currently, I see an acupuncturist monthly for continued treatment of my ankle and body alignment, during which time I practice centering prayer, a form of mindfulness. And at times, I alleviate sleep deprivation by simply sleeping during these sessions. In 
addition, I am attempting to habituate into shape by hiking with the family often tracking my daily steps by wearing a smart watch and pursuing regulated sleep times. One of the ways of meeting the multiple requirements and the various roles I inhabit while retaining space for self-care is building into my schedule contingency times.

\section{Contingency Times}

In my first doctoral coursework, Ray Anderson, the late professor of practical and systematic theology and a pastor of a multi-generational congregation, briefly shared about using contingency times to manage his various roles. I was intrigued. I made an appointment with him to learn what exactly this method was. He shared, matter-of-factly, that he built in extra time from 10 to 30-minute increments between meetings, class times, family times, worship services, and such into his schedule on a daily and weekly basis as a provision for unforeseen situations. This way, if an urgent need presented itself, he had the luxury of time to pay attention to that need. If students request a conversation after class, he could attend to them, and if congregants wanted a counseling session, he had the time to schedule one. If there were no unforeseen situations, he had the luxury of time to add to his scheduled reading and writing times or time to play b-ball with the neighborhood kids; he was in his late 70's.

I have found this wisdom enduring. Berg and Seeber cautions against the "detrimental effects of time poverty":

Time management is not about jamming as much as possible into your schedule, but eliminating as much as possible from your schedule so that you have time to get the important stuff done to a high degree of quality and with as little stress as possible. (Berg and Seeber 2016, 29)

I am learning to declutter not only my physical space (thanks to Mari Kondo), but my mind through thinking about time in a different way: I am not too busy. I have time, and I elect to do the prioritized relational pieces especially with my toddler, partner, and parents. I also select times to prepare, plan, and execute my scheduled and unscheduled work, e.g., teaching, leading, preaching, counseling, researching, and writing. Within these elected and selected times, I am learning to prioritize self-care and build in contingency times to allow for the luxury of paying attention to all aspects of my diverse relational webs.

An integrative pedagogy in which the confluence of my various roles and identities interacts with the various identities of my students require self-care and contingency times. The principles of change, contradiction, and relationship that reside in my being allows me to bring the whole of who I am to teach. Rather than striving to achieve a perfect balance through compartmentalizing all the roles I embrace, the integration of these roles and the intersubjective co-creation of the course with the students allows for significant learning such that flow is more possible in the classrooms.

\section{B I B LIOGRAPHY}

Berg, Maggie, and Barbara Karolina Seeber. 2016. The Slow Professor: Challenging the Culture of Speed in the Academy. Toronto, ON: University of Toronto Press.

Beveridge, Ivana, Robin Vallat, and Catherine De La Robertie. 2018. “Rejuvenating Strategy Research: A Yin Yang Balancing Perspective." China Media Research 14, no. 4: 67-74.

Brookfield, Stephen. 2005. Discussion as a Way of Teaching: Tools and Techniques for Democratic Classrooms. San Francisco, CA: Jossey-Bass.

Brookfield, Stephen. 2015. The Skillful Teacher: On Technique, Trust, and Responsiveness in the Classroom. San Francisco, CA: Jossey-Bass.

Burnett, Bill, and Dave Evans. 2016. Designing Your Life: How to Build a Well-Lived, Joyful Life. New York, NY: Random House.

116 2021; 2:1 113-118 The Wabash Center Journal on Teaching

This work is licensed under a Creative Commons Attribution-NonCommercial 4.0 International License 
Copeland, Adam J. 2019. "The Soft Skills of Teaching." The Christian Century, September 20. https://www. christiancentury.org/blogs/archive/2016-09/soft-skills-teaching.

Encyclopedia.com. 2019. "Csíkszentmihalyi, Mihaly.” Encyclopedia of World Biography, Encyclopedia.com. https:// www.encyclopedia.com/history/encyclopedias-almanacs-transcripts-and-maps/csikszentmihalyi-mihaly.

Fink, Dee L. 2013. Creating Significant Learning Experiences: An Integrated Approach to Designing College Courses. Hoboken, NJ: Jossey-Bass, 2013.

Knapik, Mirjam, and Ann Laverty. 2018. "Self-Care: Individual, Relational, and Political sensibilities." In Wellbeing in Higher Education, edited by Marcus Henning, Christian U. Krägeloh, and Rachel Dryer, 59-69. New York, NY: Routledge.

Peng, Kaiping, and Richard Nisbett. 1999. "Culture, Dialectics, and Reasoning About Contradiction.” American Psychologist 54, no. 9: 741-754.

Seligman, Martin. 2012. Flourish: A Visionary New Understanding of Happiness and Well-Being. New York: Atria Books, 2012.

\section{ABOUT THE AUTHOR}

Kirsten Sonkyo Oh is Professor of Practical Theology at Azusa Pacific University and the Ecclesiastical Associate Professor of United Methodist Studies at Fuller Theological Seminary. She holds a Ph.D. in Theology with emphasis in Pastoral Care and Counseling and focuses her research on intercultural narrative counseling using multidisciplinary approaches, to address the intersections of Identities. 
